\title{
Out of pocket expenditure on utilization of ante-natal and delivery care services in India: analysis based on NSSO 60th round
}

\author{
Saraswati Kerketta* \\ Department of Geography, Nistarini College, Purulia, West Bengal, India \\ Received: 05 October 2015 \\ Accepted: 21 October 2015 \\ *Correspondence: \\ Saraswati Kerketta, \\ E-mail: saraswati.kerketta@gmail.com \\ Copyright: (C) the author(s), publisher and licensee Medip Academy. This is an open-access article distributed under \\ the terms of the Creative Commons Attribution Non-Commercial License, which permits unrestricted non-commercial \\ use, distribution, and reproduction in any medium, provided the original work is properly cited.
}

\begin{abstract}
Background: Maternal mortality is a major concern in India; it can be reduced by providing reproductive health care services to the pregnant women. Out of pocket expenditure is a major barrier to the mothers in access to the maternal care services in India.

Methods: Data has been extracted from NSSO 60th round. Univariate and multivariate analysis has been carried out to examine the pattern and factors affecting out of pocket expenditure on ante natal and delivery care services in India.

Results: There are differentials between public and private health facilities in terms of out of pocket expenditure on maternal care services in India. The Logit Model explains that urban mothers are 1.6 times $(\mathrm{OR}=1.652)$ and 3.2 times $(\mathrm{OR}=3.273)$ significantly more likely of OoP expenditure on ANC and delivery Care. Among the social groups, a big difference can be seen in terms of expenditure on delivery care services. As women's educational level increases, the likelihood of out of pocket expenditure on delivery care services also increases. Women in higher age groups have more chances of out of pocket expenditure in receiving ante natal and delivery care with reference category (age <= 19). Mothers with third quintile of MPCE are 6.9 times $(\mathrm{OR}=6.983)$ and 11.5 times $(\mathrm{OR}=11.547)$ more likely of OoP expenditure on ANC and deliver care than reference category (first quintile).

Conclusions: The out of pocket expenditure is the main barrier in access to the health care services to the pregnant women. The government must ensure a free of cost institutional delivery especially to the poor mothers so that the maternal mortality can be reduced.
\end{abstract}

Keywords: Maternal Mortality, ANC, Delivery Care, Out of Pocket Expenditure, Socio-economic factors

\section{INTRODUCTION}

Utilization of maternal health care services has been recognized as a significant factor in influencing maternal and child mortality. India continues to account for a quarter of all maternal and child deaths at the world level. ${ }^{1}$ The maternal mortality rate in India has declined from 301 deaths per 100,000 live births between 2001-03 to 178 during $2011-13$, but the rate still lags behind the UN Millennium Development Goals (MDGs) of 109 by the year 2015. The progress in maternal health and reduction in maternal mortality, as envisaged in the (MDGs), critically depends on the availability, accessibility, and affordability of reproductive health services. There is a need to improve maternal health outcomes by stimulating demand for appropriate services. $^{2-4}$

Though maternal healthcare services in India are provided free of cost for delivery care in public health institutions, but many Indian families face significant outof-pocket (OoP) expenditures, which are major barriers in access to maternal health care. Thus the cost of care as a barrier to access to maternal health care services, has been frequently highlighted in many studies. ${ }^{5-7}$

Out of pocket expenditure on health care services is a significant factor in choice of the institutional facility for ante-natal and delivery care in India. Out of pocket payment is the main source of financing health care 
throughout Asia, More than $72 \%$ of expenditure on health care is financed by out of pocket in India. ${ }^{8-10}$

There are some hidden costs like - transportation cost, medicines, and other expenses, which also affect the utilisation of reproductive health care services. Some studies found that cost of travel, drugs, and hike in fees structure are negatively related with utilisation of health care services. $^{11-13}$

The cost of health care is comparatively higher in private sector than the public health facilities. Households using private inpatient services are more likely to face catastrophic expenditure. Countries relying on out-ofpocket expenditure had the highest occurrence of catastrophic payments. $^{8}$

There are some of the social groups which are more deprived and vulnerable. These social groups have less affordability to health care services because of their poverty. Out of pocket expenditure on health care services enhance their catastrophic expenditure and poverty. Similarly, the correlation between health spending and poverty has been discussed by some other studies. $^{14-17}$

\section{METHODS}

For the current paper, data has been used from the $60^{\text {th }}$ round of the National Sample Survey Organisation (NSSO). The $60^{\text {th }}$ round survey collected the samples from all over the country on household consumer expenditure, employment-unemployment situation and information related to morbidity and health care, except from some interior areas. Data on maternal health care expenditure (ante-natal care, delivery care) was collected for all the ever-married women aged 15-49 years who were pregnant during the 365 days prior to the survey.

In our paper, we used two dependent variables, i.e. 1) out of pocket expenditure on antenatal care and 2) out of pocket expenditure on delivery care. Before adopting a multivariate model, the levels of out of pocket expenditures on these two dependent variables have been examined by public and private health care sectors. Finally to study the factors affecting the expenditure on maternal health care (ANC and delivery care), multivariate analysis have been carried out.

\section{RESULTS}

Table 1 reveals that there are considerable variations across the states in terms of utilization of ante-natal and delivery care services. The utilisation of ante-natal care services ranges from a high of 96 percent in both Kerala and Tamil Nadu to a lowest 54 percent in Bihar, followed by 55 percent in Uttar Pradesh. Kerala again, followed by Goa, outperform all other states in terms of delivery care, where nearly all deliveries take place in medical institutions. Tamil Nadu, with 90 percent of deliveries takes place in medical institutions, rank third among all the states in terms of delivery care services. Nagaland, Chhattisgarh, Jharkhand, and Bihar are the states which have very poor performance in terms of utilisation of delivery care services. The percentage of women having access to institutional deliveries lies only between 12-20 percent.

Southern states such as Kerala, Tamil Nadu, Goa and Karnataka are leading states, while Empowered Action Group states (EAGs) and north-east states are performing very poorly in terms of utilisation of maternal health care services. This is due to the difference in their social and economic development and poor health care delivery system.

Table 1: Utilisation of ante-natal care and institutional delivery (\%) in India, 2004.

\begin{tabular}{|lll|}
\hline States/UTs & ANC \% & $\begin{array}{l}\text { Institutional } \\
\text { Delivery } \%\end{array}$ \\
\hline Andaman \& Nicobar & 98.8 & 76.8 \\
\hline Andhra Pradesh & 91.1 & 70.3 \\
\hline Arunachal Pradesh & 53.4 & 41.3 \\
\hline Assam & 77.7 & 41.9 \\
\hline Bihar & 54.7 & 18.4 \\
\hline Chandigarh & 71.1 & 76 \\
\hline Chhattisgarh & 72.3 & 20.2 \\
\hline Dadra Nagar Haveli & 98 & 90.7 \\
\hline Daman \& Diu & 70.8 & 61.9 \\
\hline Delhi & 78.3 & 61.3 \\
\hline Goa & 98.1 & 96.6 \\
\hline Gujarat & 80.1 & 53.7 \\
\hline Haryana & 80.6 & 33.7 \\
\hline HP & 92.7 & 61.4 \\
\hline J\&K & 80 & 56 \\
\hline Jharkhand & 56.3 & 28.9 \\
\hline Karnataka & 88.4 & 62.9 \\
\hline Kerala & 96.3 & 100 \\
\hline Lakshadweep & 87.5 & 94.7 \\
\hline Madhya Pradesh & 62.4 & 41.9 \\
\hline Maharashtra & 83.1 & 67.5 \\
\hline Manipur & 82.4 & 66.9 \\
\hline Meghalaya & 48.9 & 38.9 \\
\hline Mizoram & 91.5 & 80.7 \\
\hline Nagaland & 85.7 & 2.1 \\
\hline Orissa & 78.7 & 31.5 \\
\hline Pondicherry & 77 & 100 \\
\hline Punjab & 66.8 & 56.1 \\
\hline Rajasthan & 73.5 & 32.8 \\
\hline Sikkim & 46.5 & 45.8 \\
\hline Tamil Nadu & 96.5 & 90.9 \\
\hline Tripura & 81.8 & 59.8 \\
\hline Uttar Pradesh & 55.7 & 16.6 \\
\hline Uttaranchal & 59.1 & 8.4 \\
\hline West Bengal & 72.8 & 43.2 \\
\hline India & 2004 & \\
\hline Source: NSSO, & & \\
\hline
\end{tabular}

Source: NSSO, 60th Round, 2004 


\section{Average expenditure on maternal health care services in India}

Table 2 shows the average expenditure incurred on utilisation of maternal health care services. In India, on an average a mother has to spend around 2,700 Rupees on utilizing these services. Most of the expenditure occurred during delivery time. Though maternal health care services are provided free of cost in the public sector health facilities but even then mothers has to spend a good amount of money on utilizing these services.

Table 2: Average expenditure (in Rs.) incurred on ante-natal care, delivery care and post natal care, India, 2004

\begin{tabular}{|lcccc|}
\hline & ANC & Delivery & PNC & $\begin{array}{l}\text { Total } \\
\text { Expenditure }\end{array}$ \\
\hline $\begin{array}{l}\text { Mean } \\
(\mu)\end{array}$ & 821 & 2192 & 627 & 2696 \\
\hline $\begin{array}{l}\text { Std. } \\
\text { D. }(\sigma)\end{array}$ & 1729 & 4282 & 1366 & 5000 \\
\hline N & 5586 & 5872 & 3734 & 7343 \\
\hline
\end{tabular}

Source: Computed from NSSO, 60th Round, 2004

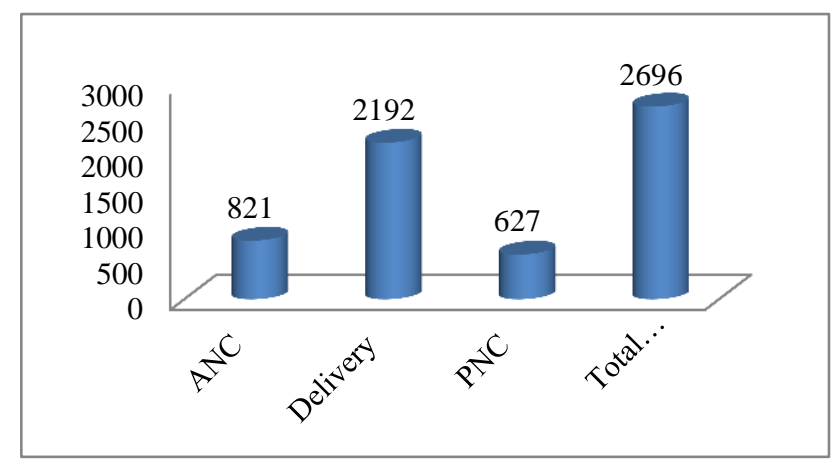

Figure 1: Average expenditure on maternal health care service in India, 2004.

It is evident from Figure 2 that only 25 percent mothers do not spend any money on utilisation of ante-natal care while the other 75 percent mothers have to spend money in receiving ante-natal care services in India. It is also clear from the figure that some of the mothers have to spend more than 1000 rupees for receiving ante-natal care services. This is a big amount for the mothers to spend on the health services prior to the delivery because at the time of delivery, again they have to spend a huge amount of money.

The main expenditure of maternal health care services is on delivery care. The Figure 3 shows that only 7 percent of total mothers do not spend any money on delivery care services, it means that 93 percent of the mothers have to spend money on the delivery care services. Around one third of the mothers have to spend more than 1,000 rupees in receiving delivery care services. This out of pocket expenditure is the main barrier for the mothers in access to institutional delivery.

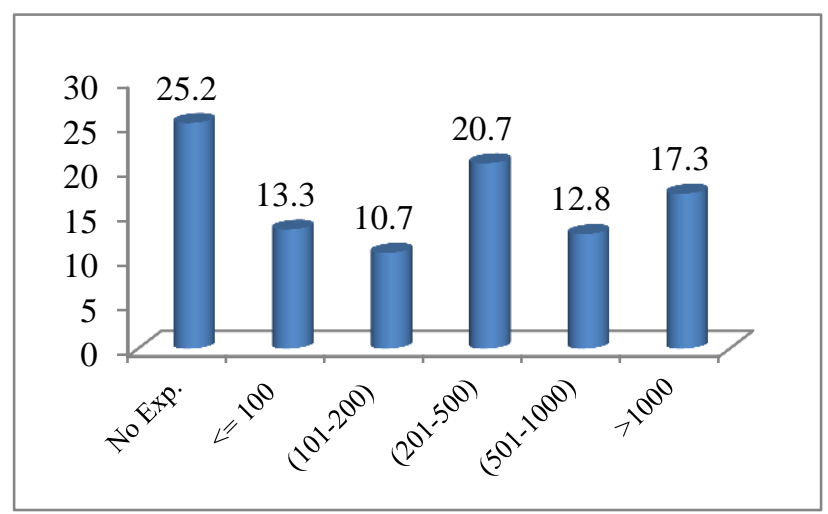

Figure 2: Out of pocket expenditure on ante-natal care service in India, 2004.

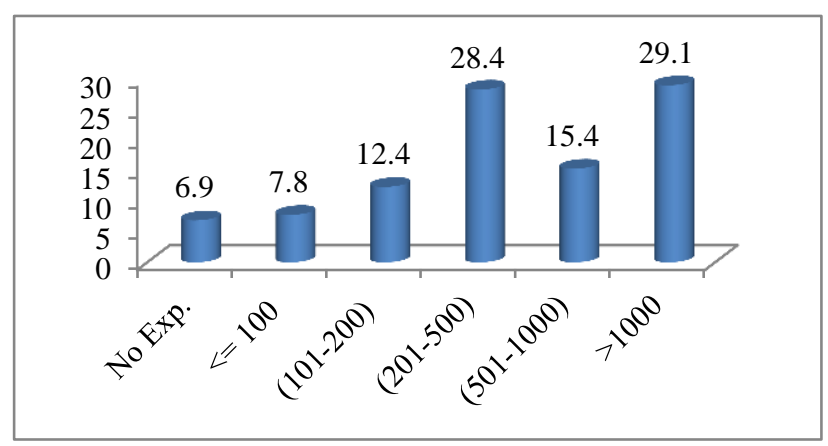

Figure 3: Out of pocket expenditure on delivery care service in India, 2004.

Out of pocket expenditure on ANC in public and private health facility

NSSO $-60^{\text {th }}$ round provides substantial information on the expenditure on utilisation of maternal health care services by private and public sector separately. Table 3 shows that around 44 percent of the mothers who choose public health facilities for receiving ante-natal care services do not spend any money. While other 56 percent women have to spend at least 200 rupees on ante-natal care services when they receive the services from public health facilities. The table 3 explains that only $2 \%$ mothers who go for the private sector do not pay for antenatal care, while other $98 \%$ mothers have to pay at least 200/- rupees for these services. It can also be noticed that around $30 \%$ of the total mothers spend more than 1,000/rupees for ante-natal care services.

Table 3: Percentage of women with expenditure on ante-natal care, 2004.

\begin{tabular}{|lll|}
\hline Expenditure in (Rs.) & Public & Private \\
\hline No expenditure & 44.7 & 2.0 \\
\hline$(<=200)$ & 25.6 & 22.5 \\
\hline$(201-500)$ & 15.4 & 26.9 \\
\hline
\end{tabular}




\begin{tabular}{|lrr|}
\hline$(501-1000)$ & 7.9 & 18.6 \\
\hline$(>1000)$ & 6.5 & 29.9 \\
\hline
\end{tabular}

Source: Computed from NSSO, 60th Round, 2004

\section{Out of pocket expenditure on delivery care in public and private health facility}

In case of expenditure on delivery care, the table 4 shows that all the mothers have to spend money on delivery care irrespective of public or private health care providers. But the amount spent on services differs much across public and private health care providers. The table below shows the amount spent in accessing delivery care services separately in public and private health institutions by expenditure-groups and it reveals that in public health institutions, almost half of the mothers (49 percent) have to spend at least 500 rupees in receiving delivery care. This is quite alarming because in India, women who access health care services from public health institutions are usually poor and spending such an amount (500 to more than 1,000) as out of pocket expenditure on delivery services can be a huge burden on their households. Not surprisingly, the mothers who opt for private health facilities for delivery care spend much more than the mothers who go for public institutions., around 85 percent of the mothers who go to private health care providers have to spend more than 1,000/- rupees for the delivery care.

Table 4: Percentage of women with expenditure on delivery care, 2004.

\begin{tabular}{|llll|}
\hline Expenditure in (Rs.) & Public & Private & Home \\
\hline No expenditure & 14.3 & 0.2 & 6.7 \\
\hline$(<=200)$ & 11.2 & 0.8 & 31.2 \\
\hline$(201-500)$ & 25.5 & 4.9 & 38.9 \\
\hline$(501-1000)$ & 21.0 & 8.9 & 16.0 \\
\hline$(>1000)$ & 28.0 & 85.1 & 7.1 \\
\hline
\end{tabular}

Source: Computed from NSSO, 60th Round, 2004

\section{Results from Multivariate Analysis}

There are certain factors which affect the expenditure on utilisation of maternal health care services and thus the expenditure on ante-natal care and delivery care varies according to these factors in a given region. To know the net effect of independent variable on dependent variables (ANC, and delivery care), binary logistic regression model has been applied. The odds ratios show the effect of one unit change in the independent variable on the odds of the response variable, keeping other variables constants. In Table 5, two models have applied separately for expenditure on ante-natal care and expenditure on delivery care.

Place of delivery has significant impact on out of pocket expenditure in receiving ante natal and delivery care services. The odds ratio show that in urban areas mothers are 1.6 times $(\mathrm{OR}=1.652)$ significantly more likely to spend money on antenatal care and 3.2 times $(\mathrm{OR}=3.273)$ more likely to spend on delivery care services in comparison to the rural mothers.

Table 5: Estimate of odds ratio in logit model for out of pocket expenditure on ante natal and delivery care services in India, 2004.

\begin{tabular}{|c|c|c|}
\hline Variables & ANC & Delivery Care \\
\hline & $\begin{array}{l}\text { Odds Ratio } \\
\text { Exp.(B) }\end{array}$ & $\begin{array}{l}\text { Odds Ratio } \\
\text { Exp.(B) }\end{array}$ \\
\hline \multicolumn{3}{|l|}{$\begin{array}{l}\text { Place of } \\
\text { Residence }\end{array}$} \\
\hline Rural ${ }^{\circledR}$ & 1 & 1 \\
\hline Urban & $1.652 *$ & $3.273 * * *$ \\
\hline \multicolumn{3}{|l|}{$\begin{array}{l}\text { Caste of the } \\
\text { women }\end{array}$} \\
\hline ST® & 1 & 1 \\
\hline SC & $1.085^{* *}$ & $1.519 *$ \\
\hline $\mathrm{OBC}$ & $1.169^{*}$ & $1.794 *$ \\
\hline Others & $1.506^{*}$ & $2.603 *$ \\
\hline \multicolumn{3}{|l|}{$\begin{array}{l}\text { Religion of the } \\
\text { women }\end{array}$} \\
\hline Hindu ${ }^{\circledR}$ & 1 & 1 \\
\hline Muslim & $.628^{*}$ & $.708^{*}$ \\
\hline Christian & 1.306 & 2.984 \\
\hline Others & .794 & 2.362 \\
\hline \multicolumn{3}{|l|}{$\begin{array}{l}\text { Education level } \\
\text { of women }\end{array}$} \\
\hline Non literate ${ }^{\circledR}$ & 1 & 1 \\
\hline Primary & $1.386^{* *}$ & $1.918 * * *$ \\
\hline Middle & $1.284 *$ & $1.916^{* * *}$ \\
\hline Secondary & $1.905^{* *}$ & $2.895^{*}$ \\
\hline $\begin{array}{l}\text { Higher } \\
\text { Secondary }\end{array}$ & $1.993 * * *$ & $2.362 * * *$ \\
\hline \multicolumn{3}{|l|}{$\begin{array}{l}\text { Age of the } \\
\text { mother }\end{array}$} \\
\hline$<19$ yrs® & 1 & 1 \\
\hline $19-34 \mathrm{yrs}$ & $1.426 * *$ & $1.521^{* * *}$ \\
\hline $35-49$ & $1.284^{*}$ & $1.579 * * *$ \\
\hline \multicolumn{3}{|l|}{ MPCE } \\
\hline First quintile ${ }^{\circledR}$ & 1 & 1 \\
\hline Second quintile & $2.509 *$ & $3.430 * *$ \\
\hline Third quintile & $6.983^{*}$ & $11.547^{*}$ \\
\hline
\end{tabular}

$*$ Sig. at $1 \%$ level, $* *$ Sig. at $5 \%$ level, $* * *$ Sig. at $10 \%$ level; (R) Reference category

Women who belong to Other Backward Caste and General community have $16 \%$ and $50 \%$ of more chances of spending money in receiving ante natal care services in comparison to the scheduled tribes which is considered as the reference category in the analysis, whereas no change was found for Schedule caste women in comparison to schedule tribe women. Among the social groups, a big difference can be seen in terms of out of pocket expenditure on delivery care services. Scheduled castes are 1.5 times $(\mathrm{OR}=1.519)$, Other Backward Castes 1.8 times $(\mathrm{OR}=1.794)$ and others are 2.6 times $(\mathrm{OR}=2.603)$ 
more likely to spend money on delivery care services than the Scheduled Castes. Muslim women are 38\% $(\mathrm{OR}=0.628)$ significantly less likely of spending money on ANC in comparison to Hindu women. On the other hand, Christian women have $30 \% \quad(\mathrm{OR}=1.306)$ more chances and women belong to other community have $21 \%(\mathrm{OR}=0.794)$ less chance of having expenditure in receiving ANC. The likelihood of expenditure on institutional delivery for Muslim women is $30 \%$ lower $(\mathrm{OR}=0.708)$, but for Christian women it is 2.9 times $(\mathrm{OR}=2.984)$ higher in comparison to Hindu women.

The probability of expenditure incurred in receiving ante natal care for women with higher secondary education is two times $(\mathrm{OR}=1.993)$ higher than that of women with no education. Similarly the mothers with secondary education are $90 \%(\mathrm{OR}=1.905)$ and with primary education $38 \%(\mathrm{OR}=1.386)$ more likely to spend money with reference to illiterate women (Reference category). As women's educational level increases, the likelihood of out of pocket expenditure on delivery care services also increases.

Age of the mother also have considerable effect on utilisation of maternal health care services, thus it also affect the out of pocket expenditure in receiving ante natal and delivery care services. Women in the age group 19-34 and 35-49 have more chances of out of pocket expenditure in receiving ante natal and delivery care with reference category (age $<=19$ ). Monthly Per Capita Expenditure (MPCE) of the household have great impact on out of expenditure on utilisation of ante natal care and delivery care services. The odds ratio shows that mothers with third quintile of MPCE are 6.9 times (OR=6.983) and 11.5 times $(\mathrm{OR}=11.547)$ more likely to spend money in receiving ante natal care and delivery care service respectively than the mother with first quintile of MPCE.

\section{DISCUSSION}

Utilization of maternal and child health care services have strong effects on subsequent use of family planning methods, and reducing maternal and child mortality. ${ }^{1}$ Although maternal healthcare services in India are offered free of cost at the point of delivery, but many Indian families face significant out-of-pocket expenditure, which is a major barrier to access to health care services. ${ }^{5-7}$

In India, on an average a mother has to spend around 2,700 Rupees on utilizing maternal care services. This shows the lack of 'free of cost' health services to the mothers. The out of pocket expenditure is the main barrier for the mothers having institutional delivery. In India most of the mothers have home delivery because of huge expenditure in health institutions especially in private health facilities. Delivery in a private health institution is about three to four times more expensive than in a public health institution. ${ }^{18}$ Similar finding were cited by some other studies. ${ }^{19,20}$
It is noticeable that in India, most of the mothers have out of pocket expenditure on ante natal and delivery care services, irrespective of public or private health institutions. Though the out of pocket expenditure has been found to be higher in private health institutions, even in public health care facilities, mothers have to spend money for receiving delivery care. ${ }^{8,18}$ In private health facility, around 85 percent of the mothers spend more than 1,000/- rupees for the delivery care.

Location of the household has significant impact on out of pocket expenditure in receiving ante natal and delivery care services. It has been found that the mothers from rural areas have more chance of catastrophic payment than the mothers residing in urban areas. ${ }^{21}$ The reason behind, most of the mothers in rural areas have home deliveries and they have very less out of pocket expenditure on delivery care services.

Women who belong to Other Backward Caste and General community have more chance of spending money in receiving ante natal care services and delivery care in comparison to reference category (Scheduled Tribe). Muslim women are less likely to spend money on ANC and delivery care in comparison to Hindu women. As the women's educational level increases, the likelihood of having expenditure on delivery care services also increases. This is because, the women with higher socio-economic status demand better health care services and they prefer to go for the private health facility. $^{14-17}$

Age of the mother also have considerable effect on utilisation of maternal health care services, thus it also affect the out of pocket expenditure in receiving ante natal and delivery care services. The women's age is negatively associated with out of pocket expenditure incurred on ante natal and delivery care. ${ }^{18}$

The mothers who belong to the higher MPCE quintile are more likely to use private health facility, and out of pocket expenditure increases with the increasing economic status of the women. The main reason behind this is that the mothers with higher economic status have more ability to pay for the services than the mothers with poor economic condition. ${ }^{18,22}$

\section{CONCLUSIONS}

The analysis shows that there are regional variations in terms of utilisation of ante natal care and delivery care services in India. Southern states are leading states, while Empowered Action Group states (EAGs) and north-east states are poorly performing. This is due to the difference in their socio and economic development and poor health care delivery system.

Mothers have to spend a good amount of money on utilizing the maternal care services. The out of pocket expenditure is the main barrier in access to the health care 
services to the pregnant women. There are great variations between public and private sector health facilities in terms of expenditure incurred on ante-natal and delivery care services. The multivariate analysis shows that socio-economic and demographic status of the mother has significant effect on out of pocket expenditure incurred on utilisation of maternal care services.

There is an urgent need to enhance the institutional delivery to reduce maternal mortality in India. For that government must ensure a free of cost delivery care system so that every woman get benefit from it. Janani Suraksha Yojana (JSY) is a good initiative of the government in this connection, which provides incentives to the mothers for the institutional delivery.

\section{Funding: No funding sources}

Conflict of interest: None declared

Ethical approval: The study was approved by the Institutional Ethics Committee

\section{REFERENCES}

1. Rama RS, Caleb L, Khan ME, Townsend JW. Safer maternal health in rural Uttar Pradesh: do primary health services contribute? Health Policy Plan. 2001;16(3):256-63.

2. Borghi J, Ensor T, Somanathan A, Lissner C, Mills A. Mobilising financial resources for maternal health. Lancet. 2006;368(9545):1457-65.

3. Martines J, Paul VK, Bhutta ZA, Koblinsky M, Soucat A, Walker N, et al. Neonatal survival: a call for action. Lancet. 2005;365(9465):1189-97.

4. Bulatao RA, Ross JA. Which health services reduce maternal mortality? Evidence from ratings of maternal health services. Trop Med Int Health. 2003;8(8):710-21.

5. Su TT, Kouyate B, Flessa S. Catastrophic household expenditure for health care in a low-income society: a study from Nouna District, Burkina Faso. Bull World Health Organ. 2006;84(1):21-7.

6. Frenk J. Bridging the divide: global lessons from evidence-based health policy in Mexico. Lancet. 2006;368(9539):954-61.

7. Musgrove P, Zeramdini R, Carrin G. Basic patterns in national health expenditure. Bull World Health Organ. 2002;80(2):134-42.

8. Van DE, O'Donnell O, Rannan ER, Somanathan A, Adhikari S, Garg C, et al. Catastrophic payments for health care in Asia. Health Economics. 2007:16(11):1159-84.

9. Devadasan N, Criel B, Van DW, Ranson K, Vander SP: Indian community health insurance schemes provide partial protection against catastrophic health expenditure. BMC Health Serv Res. 2007;7:43.
10. Ellis RP, Alam M, Gupta I. Health Insurance in India: Prognosis and Prospectus. Economic and Political Weekly. 2000;35(4):207-17.

11. Freeman DHJr., Gesler WM, Mieras BJ. A categorical data analysis of contacts with the family health clinic, Calabar, Nigeria. Social Science and Medicine. 1983;17(9):571-8.

12. Sauerborn RA, Nougtara, Diesfeld HJ. Low utilisation of community health workers: Results from a household interview survey in Burkina Faso. Social Science and Medicine. 1989;29(10):1163-74.

13. Yoder RA. Are people willing and able to pay for health services? Social Science and Medicine. 1989;29(1):35-42.

14. Wagstaff A. Poverty and health sector inequalities. Bull World Health Organ. 2002;80(2):97-105.

15. Van DE, O'Donnell O, RERP, Somanathan A, Adhikari SR, Garg CC, Harbianto D, Herrin AN, Huq MN, Ibragimova S. Effect of payments for health care on poverty estimates in 11 countries in Asia: an analysis of household survey data. Lancet. 2006;368(9544):1357-64.

16. Whitehead M, Dahlgren G, Evans T. Equity and health sector reforms: can low-income countries escape the medical poverty trap? Lancet. 2001;358(9284):833-6.

17. Whitehead M, Diderichsen F. Social capital and health: tip-toeing through the minefield of evidence. Lancet. 2001;358(9277):165-6.

18. Sanjay KM, Akanksha S. Out-of-pocket expenditure on institutional delivery in India. Health Policy and Planning. 2013;28:247-62.

19. Limwattananon S, Tangcharoensathien V, Prakongsai P. Catastrophic and poverty impacts of health payments: results from national household surveys in Thailand. Bulletin of the World Health Organization. 2007;85:600-6.

20. Kanjilal B, Mukherjee M, Singh S, Mondal S, Barman D, Mandal A. Health, equity and poverty exploring the links in West Bengal. FHS Working Paper, 2007.

21. Yardim M, Cilingiroglu N, Yardim N. Catastrophic health expenditure and impoverishment in Turkey. Health Policy. 2009;94(1):26-33.

22. World Health Organization. Health services utilization and out-of-pocket expenditure at public and private facilities in low-income countries. Geneva, Switzerland, 2010.

Cite this article as: Kerketta S. Out of pocket expenditure on utilization of ante-natal and delivery care services in India: Analysis based on NSSO 60th round. Int J Reprod Contracept Obstet Gynecol 2015;4:1704-9. 